\title{
INTRA-ARTERIAL CHEMOTHERAPY AND ITS SIGNIFICANCE IN THE TREATMENT OF OROPHARYNGEAL CARCINOMA
}

\author{
Jiri Simek $^{\mathrm{a} *}$, Jiri Ehrmann ${ }^{\mathrm{b}}$, Jindrich Pazdera ${ }^{\mathrm{a}}$ \\ a Oral, Maxillary and Facial Surgery Clinic, Faculty of Medicine and Dentistry and Teaching Hospital, Palacky University \\ Olomouc, Czech Republic \\ ${ }^{b}$ Department of Pathology, Faculty of Medicine and Dentistry and Teaching Hospital, Palacky University, Olomouc \\ e-mail: jiri.simek@yahoo.com
}

Received: September 3, 2007; Accepted: October 27, 2007

Key words: Oropharyngeal carcinoms/Intra-arterial chemotherapy

Background: In complex therapeutic algorithms for cancer, regional intra-arterial chemotherapy is usually used as an adjuvant and placed in the beginning of treatment. Clinical experience however shows that the achieved remission of malignant tumour illness after non-adjuvant chemotherapy is only temporary and short-lived. The illness progresses relatively quickly if the patient receives no further treatment and most clinical studies have not found any significant increase in life expectancy in oncological patients treated with this method. The question remains to what extent the poor results are due to the treatment method and its position in the therapeutic algorithm, and to what extent they are due to imperfect knowledge of molecular tumour genetics or inappropriate choice of the neoadjuvant intra-arterial chemotherapy

Methods: We compared preliminary results of immunohistochemical examinations (detection and analysis of expression of proteins $\mathrm{Ku}$ 70, STAT 1,3,5 which take part in the regulation of cell cycle apoptosis and repair of damaged DNA, carried out before and after chemotherapy, suggest that depending on the effects of neoadjuvant intra-arterial chemotherapy and patient's survivance.

Results and Conclusion: An overview of intra-arterial neoadjuvant chemotherapy of head and neck is presented. Knowledge of cell cycle processes, especialy apoptosis and repair of damaged DNA, could significantly influence the choice of the therapeutic algorithm and therapeutical effect.

\section{INTRODUCTION}

The incidence of oropharyngeal carcinoma in various parts of the world ranges from 1-10 cases per 100,000 inhabitants though its occurrence is extremely high in Southeast Asia.

No doubt it is influenced by genetic factors, lifestyle and level of prevention. In the Czech Republic, the occurrence of oropharyngeal carcinoma (2.6/100,000 inhabitants) corresponds to the European average for men, while it is above average in females. Surgical removal of the tumour continues to be a first choice of basic therapeutic options (surgery, radiotherapy, chemotherapy). Radiotherapy is usually placed in the end of the therapeutic cycle (adjuvant radiotherapy) or as the main therapeutic method in inoperable tumours or in tumour recurrences.

Chemotherapy has a rather adjuvant significance in the algorithm of treatment for oropharyngeal carcinoma. Systemic administration of cytostatics in combination with radiotherapy can increase tumour radiosensitivity and improve the final effect of treatment. There is no uniform view on the inclusion of chemotherapy at the beginning of combined treatment (neoadjuvant chemotherapy) with the aim of reducing tumour volume and establishing conditions for its successful surgical removal. In the area of head and neck, the tumour is relatively well supplied with blood (mostly via a.carotis ext. and its ventral branches) and it is possible to administer the cytostatic directly to the afferent artery (regional intraarterial chemotherapy). The advantages of this treatment modality involve achieving optimum concentration of cytostatic in tumour tissue, reducing the total therapeutic dose, limiting systemic side effects and cutting down the total costs of treatment.

Critics of the use of neoadjuvant inta-arterial chemotherapy in orofacial oncology point to the fact that this treatment procedure does not influence significantly the overall success of cancer treatment or survival time of patients ${ }^{2,17,18,20}$. Clinical experience has shown that the therapeutic effect of neoadjuvant chemotherapy is only temporary, relatively short-lived and cannot be estimated in advance. If a patient does not receive additional treatment for some reason, the illness progresses relatively quickly. The reasons for the time-limited effect of neoadjuvant chemotherapy are not completely clear. One possible explanation involves differences in chemotherapy-induced expression of several proteins taking part in the regulation of the tumour growth. One known negative consequence of neoadjuvant intra-arterial chemotherapy involves remission of macroscopically apparent tumour edges, which is associated with risk of insufficient radicality during subsequent surgical removal. 


\section{Indication of Intra-arterial Chemotherapy of Oropharyngal Carcinoms}

Regional intra-arterial chemotherapy is indicated in patients in stags III and IV of malignant tumour illness treatment. It should be included the beginning of complex at treatment as the first treatment modality (tumour vascularity should not be altered by previous surgical events or radiotherapy). Considering the time-limited therapeutic effects, it is not appropriate to use regional chemotherapy as a palliative treatment procedure in incurable tumours.

When assessing indications for intra-arterial chemotherapy of oropharyngeal carcinoma, the following is taken into account:

- Stage of the malign tumour illness,

- Prior therapeutic events,

- Tumour localisation,

- Overall health and age of the patient,

- Mental state of the patient, assumptions for collaboration with physician.

The patient's good health and interest in collaboration with physician are important prerequisites for successful utilisation of the method. Therefore, we do not recommend regional chemotherapy in patients with serious liver or kidney illnesses, alcoholics, uncooperative, disoriented or immobile patients.

The method is relatively safe and has a low percentage of complications, but it is still necessary to bear in mind that the insertion of an intra-arterial cannula in close vicinity to carotid (for instance in chemotherapy of laryngeal carcinoma) can be associated with increased risk of embolism in the central nervous system via a.carotis int.

\section{Intra-arterial Chemotherapy Technique}

Intra-arterial chemotherapy is principally based on administration of cytostatic to the area which is supplied by an appropriate artery. In the orofacial area, this mostly involves one of the ventral branches of a. carotis externa (according to the localisation of the tumour). A cannula is inserted

- directly into an appropriate artery (direct method),

- to a. carotis externa via a. thyroidea sup. (indirect method),

- to a. carotis externa via a. temporalis superfic. (retrograde method).

An alternative method consists in the use of a portcatheter, implanted into subcutis in the area of the mastoid process or under the clavicle, and leading into chosen artery.

Of the above, it seems most advantageous to use retrograde cannulation via a. temporalis superficialis. The blood vessel is accessed via a $4-5 \mathrm{~cm}$ long vertical skin incision, approximately $1 \mathrm{~cm}$ forward of tragus (ear). Following arteriotomy, we insert the cannula approximately $10 \mathrm{~cm}$, check the correct localisation of the cannula and the range of perfused area perisurgically using a colorimetric test (Patentblau). It is also possible to check the position of the cannula arteriographically, but it is much more demanding from a technical and financial point of view. Then, we secure the cannula with stitches and connect it to an infusion pump. The infusion solution (physiological solution, 5\% glucose solution) contains a cytostatic as well as low-molecular heparin and an analgetic with a spasmolytic effect (e.g. Prokain). Movement of patient during a treatment cycle, which lasts for 6-8 days, is spatially limited. In any event, the range of extension of the infusion allows him/her to move around the room with access to washbowl and toilet. The advantage and pitfalls of regional intra-arterial chemotherapy are given in Table 1.

The complications marked in italics are marked enough to discontinue treatment prematurely.

Table 1. Advantages and pitfalls of regional intra-arterial chemotherapy

\begin{tabular}{|l|l|}
\hline \multicolumn{1}{|c|}{ Advantages of intra-arterial chemotherapy } & \multicolumn{1}{c|}{ Disadvantages of intra-arterial chemotherapy } \\
\hline $\begin{array}{l}\text { Achieving optimum concentration of the cytostatic in } \\
\text { tumour tissue }\end{array}$ & Short-term therapeutic effect \\
\hline $\begin{array}{l}\text { Reduction of the total dose of a cytostatic } \\
\text { lower system toxicity }\end{array}$ & $\begin{array}{l}\text { Risk of intra-arterial thrombosis with subsequent vascular } \\
\text { brain accident }\end{array}$ \\
\hline $\begin{array}{l}\text { Lowering the risk of system side effects, financial } \\
\text { savings }\end{array}$ & $\begin{array}{l}\text { Regional skin and mucous reaction } \\
\text { (dermatitis, stomatitis, alopecia) }\end{array}$ \\
\hline & $\begin{array}{l}\text { Unpleasant subjective feelings (burning etc.) } \\
\text { in the perfused area }\end{array}$ \\
\hline & $\begin{array}{l}\text { Technical complications } \\
\text { (dislocation or obturation of intra-arterial cannula) }\end{array}$ \\
\hline
\end{tabular}


Cytostatics suitable for use in regional intra-arterial chemotherapy are divided according to their chemical composition and mechanism of interference with the cellular cycle (Tab. 2)

Table 2. Classification of cytostatics by mechanism of effect

\begin{tabular}{|l|}
\hline Antimetabolites (MTX, 5-FU) \\
\hline Alkylating substances (DDP) \\
\hline Substances with radiomimetic effect (BLM) \\
\hline Mitosis inhibitors (VCR, taxanes) \\
\hline
\end{tabular}

Folic Acid Analogues (Antifolics)

\section{Metotrexate (MTX)}

The MTX mechanism is based on competitive inhibition of dihydropholate reductase, which transforms folic acid (or, more accurately, dihydrofolic acid) into tetrahydrofolic acid, an important cofactor in the biosynthesis of purines. The final effect involves a blockade of DNA synthesis and cell division. Dihydrofolate reductase inhibition can be prevented by simultaneous delivery of reduced folates (folinic acid, leucovorin), which are used in practice as chemoprotectives. MTX selectively inhibits cell division in the S-phase of the cell cycle, and actively proliferating tissues are more sensitive to the effects of the antimetabolite. The cytostatic penetrates the cell via an active transport mechanism but in cases of impaired function it causes resistance to MTX in tumour cells ${ }^{1,6,27}$. This can be overcome by increasing the dose of cytostatic and concurrent administration of leucovorin as a chemoprotective.

\section{Pyrimidine analogues (uracil analogues, fluroinated pyrimidines)}

5-fluoruracil (5-FU) is a pyrimidine antimetabolite with a multiple manner of interference with DNA biosynthesis. In the cell cycle, it especially acts in the S-phase, and partly slows down the transition G1-S. Antitumour effects can be reinforced by concurrent administration of reduced folates (leucovorin). 5-fluorouracil metabolises quickly in the body (in liver) to dihydro-5-fluorouracil; approximately $20 \%$ is excreted in urine in an unchanged form (the half-time is 10-15 minutes). The swift decline in plasma concentration after single administration explains why continual infusion manifests more marked antitumour efficiency ${ }^{8,10,12,13 .}$

\section{Platinum derivatives}

Cisplatin (DDP) has a similar mechanism to alkylating compounds. These bind with the nitrogen in purine and pyrimidine in the DNA molecule. DDP potentiates the cytotoxic effect of many other cytostatics (vincristin, vinblastin, 5-flourouracil) $)^{30,32}$ and has specificity for any phase of the cell cycle. It has marked immunosuppressive effects. After systemic administration, DDP is transported to tissues very swiftly and concentrates especially in kidney, liver and gonads. It is excreted into urine in three phases. The half time of the rapid phase is $8-50$ minutes, 16 hours for the medium phase and 5 days for the slow phase. In hydrous solution, especially with alkaline $\mathrm{pH}$, hydrolysis occurs at a rate which can restrict higher concentrations of chloride ions. This is why a physiological or Ringer's solution is used for infusion treatment and not the $5 \%$ glucose. A serious undesirable effect of DDP is nephrotoxicity which can be eliminated by correct hydration regime.

Carboplatin is a second-generation cisplatin derivative. It is a cytostatic effective in the treatment of a wide spectrum of malignant neoplasms. The biochemical properties and the mechanisms of effect are similar to those of DDP. The antitumour activity of platinum derivatives is mostly based in DNA synthesis inhibition; however, participation of other mechanisms, e.g. immunosuppressive or radiosensibilising ones, cannot be excluded.

\section{Substances with a radiomimetic effect}

Bleomycin (BLM) is a polypeptide antibiotic isolated from Streptomyces verticillus. It has weak antimicrobial and marked cancerostatic effects. The exact mechanism of its effect is unknown but the results of its action resemble the effects of radioactive radiation. It mainly functions in the G2-phase of the cell cycle. BLM is mostly metabolised in kidney and liver.

\section{Mitosis inhibitors}

Vinca alkaloids are preparations that damage the structure and function of the microtubules of the dividing spindle which provides for correct migration of chromosomes prior to cell division. Most of these cytostatics restrict the synthesis of tubulin, the protein of which the spindle is built. The vinca alkaloids block the mitosis process by inhibiting the production, or destruction, of microtubules. Vinblastin has a synergistic effect with Bleomicin. Vincristin (VCR) has similar chemical and physical properties, is phase-specific, influences permeability of membranes and hence potentiates the effect of other cytostatics.

Taxans (taxoids) represent a relatively new group of substances with an antitumour effect. They involve substances of natural origin isolated from yew (Taxus breviofolia, Taxus baccata). Taxans cause mitosis inhibition by blockade of tubulin depolymerisation. Taxans also block the transition from the G2-M-phase and have a radiopotentiating effect, as the cells, which occur at this phase, are more vulnerable to ionising radiation. They then block the cell response to growth factors, inhibit production of the "tumour necrosis factor" and are mediators of apoptosis. They have been produced synthetically since 1994 (e.g. Paclitaxel, Docetaxel, Taxol)

The mechanism of antitumor activity of paclitaxel is not known exactly ${ }^{30,32}$. It has been reported to support the aggregation of microtubules from tubulin dimers to prevent their depolymerisation. The subsequent stabilisation 
then results in the inhibition of normal dynamic reorganisation of the microtubular assembly, necessary for interphase and mitotic cell functions. It then induces abnormal arrangement of microtubules leading to the development of multiple microtubular asters during mitosis. After administration, 88-98\% bind to plasma proteins, and the plasma concentration decreases in a biphasic manner. The large distribution indicates extensive extravascular or binding to tissue. Renal excretion is not significant in the case of paclitaxel: less than $10 \%$ of the dose administered is excreted unchanged in urine. Metabolism with subsequent excretion into bile is the main elimination route.

\section{Choice and algorithm of cytostatic administration in regional intra-arterial chemotherapy}

Chemotherapy of oropharyngeal carcinoma began to be used clinically in the 1960s. The results of monotherapy were not very encouraging. A combination of Metotrexat and Bleomycin in various regimes was then used. $15-50 \%$ remission was achieved in this manner. The introduction of cisplatin and its analogues was another step forward. The first results of the use of cisplatin reported 30-50\% remissions, and 30-40\% of remissions with carboplatin. A combination of DDP, MTX, BLE, 5-FLU produced 15-30\% remissions. Clinical studies report $70-90 \%$ of remissions, with an unusual percentage of 20-50\% of complete remissions. We must emphasize that only patients in T3/T4 stages participated in most of the studies. Some results of non-randomised studies from available literature are given in Table 3.

The table shows that combinations DDP+FU, $\mathrm{DDP}+\mathrm{BLM}, \mathrm{DDP}+\mathrm{BLEO}+\mathrm{MTX}$ were the most successful $^{4,31}$. In the 1990 s, promising results using taxans (Paclitaxel) in combination with carboplatin were reported. Nevertheless, an analysis of the results showed that no randomised, well-designed study has demonstrated the contribution of chemotherapy to survival extension in oncological patients.

\section{Significance of immunohistochemical examination for an estimation of the effect of chemotherapy}

One possibility for evaluating in advance the reaction of cells to treatment is to determine the level of TPS marker or acid phosphatase. TPS is a non-specific marker which responds to the increased proliferating activity of cells in the S2-phase of mitosis. Comparing the TPS level at the beginning and during treatment shows a reduction in TPS level when the response is positive (approximately $70 \%$ success). At the same time, the activity of the acid phosphatase also increases with increasing damage to tumour. It would be much more useful to know the response of tumour prior to treatment and thus modify the therapy be optimal. The approach could to consist in the detection and analysis of the expression of selected regulators of the cell cycle of malignant tumours (Ka70, STAT 1,3,5), which are significant for tumour invasivity and development of antitumor immunity. Similarly, genetic screening (comparing genetic damage and response to cytostatic treatment) can assist in determining the chemosensitivity of tumour cells. This method seems very promising and if it is successful, one could speak of targeted cytostatic treatment (comparable to the relationship between bacteria cultivation and microbiological examination with targeted antibiotic treatment).

\section{CONCLUSION}

Intra-arterial neoadjuvant chemotherapy of head and neck tumours has held an irreplaceable position in the treatment of oncological illnesses of the orofacial area. Especially in the beginning of the 1960s, it was considered a huge step forward and it could have seemed that the issue of tumour treatment was "resolved" to a certain degree. As with any other new treatment method however, the advantages and complications emerged over time.

Table 3.

\begin{tabular}{|l|l|l|l|c|}
\hline \multicolumn{1}{|c|}{ Author } & Year & \multicolumn{1}{|c|}{ Combination } & Number of patients & $\begin{array}{c}\text { \% (complete/partial } \\
\text { remission) }\end{array}$ \\
\hline Jacobs (11) & 1987 & DDP+FU & 30 & 85 \\
\hline Schuller(21) & 1984 & & 83 & 65 \\
\hline Greenberg(8,9) & 1987 & DDP+FU & 40 & 75 \\
\hline Spaulding(23) & 1986 & DDP+FU+VBL & 72 & 80 \\
\hline Vingnoud & 1987 & DDP+FU & 26 & 90 \\
\hline Mechl jun.(22,24,15) & 1990 & DDP+FU & 59 & 67 \\
\hline Hasegava & 1994 & DDP+FU & 50 & 59 \\
\hline Lehman & 1994 & DDP+FU & 55 & 65 \\
\hline Berocar & 1993 & DDP+IFO & 26 & 66 \\
\hline Pai (16) & 1993 & DDP+IFO & 76 & 66 \\
\hline
\end{tabular}


Moreover, it has become apparent that tumour volume reduction (which is only partial in an overwhelming majority of cases) is only temporary. In more than $90 \%$ of cases, the effect is short-term and the tumour progresses again in several weeks ${ }^{3,25}$. For this reason chemotherapy began to be used as an adjuvant at the beginning of complex antitumor treatment.

The initial optimism, associated with the introduction of regional intra-arterial chemotherapy when tumours responded very well to treatment with cytostatics (e.g. Bleomycin), was replaced by scepticism ${ }^{5,26,29}$. We currently often encounter zero therapeutic response or even a progression of the tumoral illness during chemotherapy. This explains why there have been efforts to determine tumour chemosensitivity prior to treatment.

An opinion which cast doubts on the therapeutic significance of regional intra-arterial chemotherapy has prevailed over the last two decades ${ }^{28}$. This follows from the fact that no clinical study has found any extension of life-span in oncological patients treated using this method. Nonetheless, we can still ask today to what extent the poor results not below are due to the treatment method and its inclusion in the therapeutic algorithm, and to what extent they are conditioned by imperfect knowledge of molecular tumour genetics or inappropriate choice of cytostatic.

\section{REFERENCES}

1. Abele R, Honegger HP, Grossenbacher R, Mermillod B, Kaplan E, Gervasi A et al. A randomized study of methotrexate, bleomycin, hydroxyurea with versus without cisplatin in patients with previously untreated and recurrent squamous cell carcinoma of the head and neck European Journal of Cancer \& Clinical Oncology 1987; 23(1):47-53.

2. Adelstein D, LeBlanc M. Does Induction Chemotherapy Have a Role in the Management of Locoregionally Advanced Squamous Cell Head and Neck Cancer? Journal of Clinical Oncology 2006; 24(17):2624-2628.

3. Advani SH, Gopal R, Saikia T, Pai VR. Induction chemotherapy in head and neck cancer: present status and future. Seminars in Surgical Oncology 1989; 5(5):337-40.

4. Argiris A, Jayaram P, Pichardo D. Revisiting induction chemotherapy for head and neck cancer: References and reviews. Oncology (Huntington) 2005; 19(7):932-934+939.

5. Bierman HR. Some problems of anti-neoplastic chemotherapy. Proceedings of the Western Pharmacology Society 1961; 4:1-3.

6. Forastiere AA, Metch B, Schuller DE, Ensley JF, Hutchins LF, Triozzi $\mathrm{P}$ at al. Randomized comparison of cisplatin plus fluorouracil and carboplatin plus fluorouracil versus methotrexate in advanced squamous-cell carcinoma of the head and neck: a Southwest Oncology Group study Journal of Clinical Oncology 1992; 10(8):1245-51.

7. Grandis JR, Pietenpol JA, Greenberger JS, Pelroy RA, Mohla S. Head and neck cancer: meeting summary and research opportunities. Cancer Research 2004; 64(21):8126-9.

8. Greenberg B, Ahmann F, Garewal H, Koopmann C, Coulthard $\mathrm{S}$ et al. Neoadjuvant therapy for advanced head and neck cancer with allopurinol-modulated high dose 5-fluorouracil and cisplatin. A phase I-II study. Cancer 1987; 59(11):1860-5.

9. Greenberg BR. Chemotherapy of squamous cell carcinoma of the head and neck. Arizona Medicine 1985; 42(7):411-7.

10. Hussain M, Benedetti J, Smith RE, Rodriguez GI, Schuller D, Ensley J. Evaluation of 96-hour infusion fluorouracil plus cisplatin in combination with alpha interferon for patients with advanced squamous cell carcinoma of the head and neck: a Southwest Oncology Group study. Cancer 1995; 76(7):1233-7.

11. Jacobs JR, Weaver A, Ahmed K, Crissman J, Ensley JF, Kish JA. Cummings G. al-Sarraf M. Proto-chemotherapy in advanced head and neck cancer. Head \& Neck Surgery 1987; 10(2):93-8.

12. Jassem J, Gyergyay F, Kerpel-Fronius S, Nagykalnai T, Baumohl $\mathrm{J}$, Verweij $\mathbf{J}$ et al. Combination of daily 4-h infusion of 5-fluorouracil and cisplatin in the treatment of advanced head and neck squamous-cell carcinoma: a South-East European Oncology Group study. Cancer Chemotherapy \& Pharmacology 1993; 31(6):48994.

13. Kish JA, Ensley JF, Jacobs JR, Binns P, al-Sarraf M. Evaluation of high-dose cisplatin and 5-FU infusion as initial therapy in advanced head and neck cancer. American Journal of Clinical Oncology 1988; 11(5):553-7.

14. Klopp CT, Alford TC, Bateman J, Berry GN, Winship T. Fractionated intra-arterial cancer; chemotherapy with methyl bis amine hydrochloride; a preliminary report. Annals of Surgery 1950; 132(4):811-32.

15. Kostřica R, Smilek P, Hložek J, Spurný V, Mechl Z. Současná komplexní léčba nádorů krku, MU v Brně, LF, edice kontinuálního vzdělávání v medicíně 2003.

16. Pai VR, Parikh DM, Mazumdar AT, Rao RS. Phase II study of high-dose ifosfamide as a single agent and in combination with cisplatin in the treatment of advanced and/or recurrent squamous cell carcinoma of head and neck Oncology 1993; 50(2):86-91.

17. Papadimitrakopoulou VA, Ginsberg LE, Garden AS, Kies MS, Glisson BS, Diaz EM Jr et al. Intraarterial cisplatin with intravenous paclitaxel and ifosfamide as an organ-preservation approach in patients with paranasal sinus carcinoma. Cancer 2003; 98(10):2214-23.

18. Poulsen M, Aldren Ch, Tripcony L, Walker Q. Is Surgery Necessary in Stage III and Stage IV Cancer of the Head and Neck That Responds to Induction Chemotherapy? Archives of Otolaryngology Head \& Neck Surgery 1996; 122(5):467-471.

19. Psyrri A, Kwong M, DiStasio S, Lekakis L, Kassar M, Sasaki et al. Cisplatin, Fluorouracil, and Leucovorin Induction Chemotherapy Followed by Concurrent Cisplatin Chemoradiotherapy for Organ Preservation and Cure in Patients With Advanced Head and Neck Cancer: Long-Term Follow-Up. Journal of Clinical Oncology 2004; 22(15):3061-3069.

20. Psyrri A, Fountzilas G. Advances in the Treatment of Locally Advanced Non-Nasopharyngeal Squamous Cell Carcinoma of the Head and Neck Region. Medical Oncology 2006; 23(1):1-15.

21. Schuller DE, Laramore G, Al-Sarraf M, Jacobs J, Pajak TF. Combined therapy for resectable head and neck cancer. A phase 3 intergroup study. Multicenter Study. Randomized Archives of Otolaryngology - Head \& Neck Surgery 1989; 115(3):364-8.

22. Smilek P, Kostřica R, Spurný V, Mechl Z. Maligní nádory hlavy a krku Diagnostické a léčebné postupy u maligních chorob 2004; 27-39.

23. Spaulding M, Ziegler P, Sundquist N, Klotch D, Lee K, Khan A, Lore J. Induction therapy in head and neck cancer. A comparison of two regiment,Cancer 1986; 57(6):1110-4.

24. Spurný V, Mechl Z, Červená R. Současné možnosti chemoterapie nádorů oblasti hlavy a krku. Klinická onkologie 2003; 16:10-18.

25. Sullivan RD, Watkins E Jr. Cancer chemotherapy by protracted arterial infusion. Arizona Medicine 1965; 22(10):791-6.

26. Sullivan RD, Watkins E Jr. Protractedarterial infusion cancer chemotherapy, Acta Unio Internationalis Contra Cancrum 1964; 20:480-3.

27. Sullivan RD, Miller E, Sikes MP. Antimetabolite-metabolite combination cancer chemotherapy. Effects of intraarterial methotrexateintramuscular Citrovorum factor therapy in human cancer. Cancer 1959; 12:1248-62.

28. Sullivan RD. Continuous arterial infusion cancer chemotherapy. Rhode Island Medical Journal 1961; 44:581-6.

29. Sullivan RD, Watkins E Jr. Cancer chemotherapy by protracted arterial infusion. Arizona Medicine 1965; 22(10):791-6.

30. Tsao AS, Garden AS, Kies MS, Morrison W, Feng L, Lee JJ et al. Phase I/II study of docetaxel, cisplatin, and concomitant boost 
radiation for locally advanced squamous cell cancer of the head and neck. Journal of Clinical Oncology 2006; 24(25):4163-9.

31. Verweij J, de Jong P, Mulder P, van der Broek P, Alexieva-Figusch J, van Putten W et al. Induction Chemotherapy with Cisplatin and Continuous Infusion 5-Fluorouracil in Locally Far-Advanced Head and Neck Cancer. American Journal of Clinical Oncology 1989; 12(5):420-424.

32. Wong ASC, Soo RA, Lu JJ, Loh KS, Tan KS, Hsieh WS et al. Paclitaxel, 5-fluorouracil and hydroxyurea concurrent with radiation in locally advanced nasopharyngeal carcinoma. ,Annals of Oncology 2006; 17(7):1152-1157. 